\title{
Diaphragm strength in patients with recent hemidiaphragm paralysis
}

\author{
CLARE M LAROCHE, ANNE K MIER, JOHN MOXHAM, MALCOLM GREEN
}

From the Respiratory Muscle Laboratory, Brompton Hospital, London

ABSTRACT Eleven patients with unilateral diaphragm paralysis of recent onset were studied to $\frac{\omega}{\omega}$ investigate the effect of the paralysis on inspiratory muscle function. Nine of the patients had noticed $\vec{\nabla}$ a decrease in exercise tolerance, which was not explained by any other pathological condition.

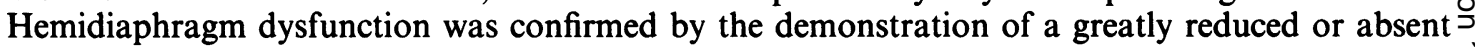
transdiaphragmatic pressure on stimulation of the phrenic nerve in the neck, by means of surface $\frac{-}{3}$ bipolar electrodes (unilateral twitch Pdi), compared with normal values on the contralateral side. $\frac{M}{3}$ Transdiaphragmatic pressure was $44.6 \%(9 \cdot 4 \%)$ predicted during a maximal sniff and $30 \cdot 3 \% \stackrel{\text { S }}{工}$ $(16.8 \%)$ predicted during a maximal static inspiration against a closed airway, confirming diaphragm $\vec{\oplus}$ weakness. Maximum static inspiratory mouth pressures were also low $(61 \cdot 7 \%(12 \cdot 7 \%)$ predicted), $\infty$ consistent with a reduction in inspiratory muscle capacity. Phrenic nerve conduction time was prolonged on the affected side in nine patients, consistent with phrenic nerve dysfunction, whereas on the unaffected side it was normal. It is concluded that recent hemidiaphragm paralysis causes a reduction in transdiaphragmatic pressure that is associated with a reduction in maximum inspiratory mouth pressure. Phrenic nerve stimulation is a useful technique with which to confirm and quantify $\stackrel{\mathbb{}}{\varrho}$ hemidiaphragm dysfunction. Measurement of phrenic nerve conduction time provides useful $\overrightarrow{\bar{O}}$ information about the underlying pathology.

Pulmonary function has been extensively studied in patients with unilateral diaphragmatic paralysis,' although the effect on inspiratory muscle function has been little reported. One recent study investigated patients with longstanding unilateral diaphragm elevation ${ }^{2}$ and found variable effects. Maximal transdiaphragmatic pressure (Pdimax) was normal in 27\% and maximal inspiratory mouth pressure (Pimax) normal in $40 \%$ of patients. ${ }^{2}$ It was suggested that the normal respiratory muscle strength found in some patients was due to mechanisms such as hypertrophy of the contralateral hemidiaphragm and increased stiffness of the paralysed side, which compensated for the unilateral diaphragm paralysis. In this study, however, hemidiaphragm paralysis was not necessarily present in all cases, as it was inferred from the presence of an elevated hemidiaphragm on the chest radiograph and a positive result in the sniff test on fluoroscopy, both of which are recognised to be associated with a considerable false positive rate. ${ }^{3}$

Address for reprint requests: $\operatorname{Dr} \mathrm{C} M$ Laroche, Respiratory Muscle Laboratory, Brompton Hospital, London SW3 6HP.

Accepted 24 December 1987
We have therefore studied maximal respiratory pressures and transdiaphragmatic pressures in $11 \stackrel{0}{x}$ patients in whom hemidiaphragm elevation was known to be recent, to investigate its effect on 3 diaphragmatic and inspiratory muscle function before 8 any compensatory mechanisms were likely to have occurred. We confirmed hemidiaphragm paralysis oro severe dysfunction by measuring transdiaphragmatic $\triangle$ pressure during stimulation of the phrenic nerve in the neck (unilateral twitch Pdi). In addition, we assessed phrenic nerve function by measuring phrenic nerve conduction time.

\section{Methods}

We studied patients with a raised hemidiaphragm of recent onset (table 1). All had had a normal chest $\stackrel{\infty}{+}$ radiograph within the previous year, confirming that 0 paralysis was recent and excluding congenital eventra- $\overline{0}$ tion. Patients $1-4$ had developed unilateral diaphragm $\stackrel{\odot}{\odot}$ paralysis after cardiac surgery, presumably as a result $\vec{\Phi}$ of phrenic nerve injury; patients 5-9 had developed it $\frac{\varrho}{0}$ after a chest infection, and patient 10 after manipulation of his neck. In patient 11 the cause was unclear; it 
Table 1 Details of patients with raised hemidiaphragm

\begin{tabular}{|c|c|c|c|c|c|c|}
\hline No & Side & Cause & $\begin{array}{l}\text { Dyspnoea } \\
\text { MRC scale }\end{array}$ & Orthopnoea & $\begin{array}{l}\text { Other pathological } \\
\text { conditions }\end{array}$ & $\begin{array}{l}F E V_{1} / F V C \\
(\%)\end{array}$ \\
\hline $\begin{array}{l}1 \\
2 \\
3 \\
4 \\
5 \\
6 \\
7 \\
8 \\
9 \\
10 \\
11\end{array}$ & $\begin{array}{l}\text { L } \\
\text { L } \\
\text { L } \\
\text { R } \\
\text { L } \\
\text { L } \\
\text { R } \\
\text { L } \\
\text { L } \\
\text { L } \\
\text { R }\end{array}$ & $\begin{array}{l}\text { Aortic VR } \\
\text { Aortic VR } \\
\text { Aortic VR } \\
\text { CABG } \\
\text { Infection } \\
\text { Infection } \\
\text { Infection } \\
\text { Infection } \\
\text { Infection } \\
\text { Cervical } \\
\text { Idiopathic }\end{array}$ & $\begin{array}{l}4 \\
2 \\
4 \\
4 \\
3 \\
2 \\
1 \\
2 \\
2 \\
1 \text { (singing) } \\
3\end{array}$ & $\begin{array}{l}0 \\
0 \\
+ \\
++ \\
0 \\
0 \\
0 \\
0 \\
0 \\
0 \\
0\end{array}$ & $\begin{array}{l}\text { Emphysema } \\
\text { Ex-smoker } \\
\text { Emphysema } \\
\text { Ischaemic heart disease } \\
\text { Moderate asthma } \\
\text { Bronchial hyperreactivity } \\
\text { None } \\
\text { None } \\
\text { Ex-smoker } \\
\text { None } \\
\text { Chronic bronchitis }\end{array}$ & $\begin{array}{l}55 \\
78 \\
38 \\
67 \\
59 \\
75 \\
90 \\
78 \\
73 \\
81 \\
51\end{array}$ \\
\hline
\end{tabular}

VR-valve replacement; CABG—coronary artery bypass graft.

had started at some time within 12 months of a normal chest radiograph.

In three of the 11 patients no other pathological condition was present and in two (Nos 2 and 9) there were mild spirometric abnormalities assumed to be related to smoking. One patient (No 5) had moderately severe asthma and another (No 6) had bronchial hyperreactivity after the chest infection during which the unilateral diaphragm paralysis had developed. Two patients had emphysema (No 1 and 3 ), and one moderate airways obstruction related to chronic bronchitis (No 11). One patient (No 4) has ischaemic heart disease.

Four patients underwent fibreoptic bronchoscopy to exclude bronchogenic neoplasm.

Breathlessness was expressed in terms of the Medical Research Council (MRC) disability scale of 1 (no breathlessness) to 5 (breathlessness on minimal exertion).

Fluoroscopic diaphragm screening was carried out in all patients, supine, during a maximal sniff. Vital capacity (VC) was measured in both the sitting and the supine posture with a rolling seal spirometer (Spiroflow), the change in VC when the patient became supine being expressed as a percentage of the value for the sitting posture ("supine fall in VC"). Absolute lung volumes were measured in a constant volume whole body plethysmograph. The forced expiratory volume in one second $\left(\mathrm{FEV}_{1}\right)$ and forced vital capacity (FVC) were measured from a forced expiration into the rolling seal spirometer. All volumes were corrected to BTPS. The transfer factor for carbon monoxide (TLCO) and transfer coefficient (KCO) were determined by the single breath method.

Global respiratory muscle strength was assessed by measuring static maximal expiratory (PEmax) and inspiratory (PImax) pressures at the mouth. Efforts were initiated at total lung capacity and residual volume respectively, the method being based on that of Black and Hyatt, ${ }^{4}$ and the results were compared with the values for 80 normal subjects studied in this laboratory. Measurements were repeated until a reproducible value was obtained for each (usually after about six attempts). Oesophageal (Poes) and gastric (Pgas) pressures were measured with balloon catheter systems connected to Validyne pressure transducers (model MP 45-1; range $\pm 150 \mathrm{~cm} \mathrm{H}_{2} \mathrm{O}$ ). Each balloon was $10 \mathrm{~cm}$ long and $3.5 \mathrm{~cm}$ in circumference. The oesophageal balloon was positioned in the mid oesophagus and contained $0.5 \mathrm{ml}$ of air. The tip of the gastric balloon was positioned $65 \mathrm{~cm}$ from the nares and the balloon contained $2.0 \mathrm{ml}$ of air.

Transdiaphragmatic pressure (Pdi) was derived electronically according to the equation Pdi $=$ Pga-Poes ${ }^{5}$ but with Pdi at resting end expiration as zero reference point. Diaphragm strength was assessed by measuring Pdi during a maximal static inspiratory effort at residual volume against a closed valve (PdiPımax) and during a short, sharp maximal sniff (sniff Pdi) ${ }^{6}$ Sniffs were performed at functional residual capacity without a noseclip and were repeated with pauses of at least 10 seconds between each sniff until a reproducible value of peak sniff Pdi was obtained (usually about six sniffs). Ten consecutive sniffs were then recorded and the greatest value was taken as the maximal sniff Pdi.

The phrenic nerves were stimulated in the neck with bipolar surface electrodes at the posterior border of the sternomastoid muscle by means of square wave impulses $0.1 \mathrm{~ms}$ in duration, with a frequency of $1 \mathrm{~Hz}$ and supramaximal voltage. Each phrenic nerve was stimulated in turn and the twitch Pdi measured for each side. Bilateral twitch Pdi was then measured during stimulation of both phrenic nerves simultaneously. On average 30 maximum twitches were measured on each occasion, the actual recorded result being the mean of the 10 largest twitches. Phrenic nerve conduction time (inversely related to nerve velocity) was measured with surface electrodes in the 7th and 8th intercostal spaces to record diaphragm evoked action potentials from the electromyogram and taken as the time interval between the initial 
stimulation and the beginning of the action potential on the electromyogram.

Signals were recorded on an eight channel strip chart recorder (Mingograph 800, Siemens) and stored on a magnetic tape recorder (Racal Store 7) for later playback and analysis.

\section{Results}

Breathlessness expressed according to the MRC scale is shown in table 1 . Only two patients had noticed no breathlessness or decrease in exercise tolerance (Nos 7 and 10) and one of these did notice slight breathlessness while singing. The other nine patients had all noticed an increase in breathlessness that was not explained by a deterioration in other pathological conditions.

Under fluoroscopic screening when supine all patients showed paradoxical movement of the affected hemidiaphragm on sniffing. In seven patients vital $\stackrel{\bar{s}}{+}$ capacity was less than $75 \%$ predicted (table 2), but in the four remaining patients it was normal. ${ }^{7}$ The mean fall in vital capacity with the change to the supine $\frac{\bar{\rho}}{\partial}$ posture was within normal limits in all patients $(12 \% \stackrel{\odot}{\complement}$ $(8 \%)$, normal $\left.<25 \%{ }^{8}\right)$ ). $\mathrm{FEV}_{\text {, }}$ ranged from $35 \%$ to $101 \%$ (mean $65 \%$ predicted) and $\mathrm{FEV}_{1} / \mathrm{FVC}$ was less than $75 \%$ in six patients (table 1). Total lung capacity. was measured in nine patients (table 2) and was $\vec{\omega}$ reduced to less than $75 \%$ predicted $^{7}$ in two (Nos 4 and ${ }^{\circ}$ 6). Residual volume was greater than $125 \%$ predicted $^{7} \vec{x}$ in two patients (Nos 3 and 5) and in each this was attributable to airways obstruction. TLCo was less $\underset{\omega}{\omega}$ than $75 \%$ predicted $^{7}$ in six patients out of nine; $\overrightarrow{-}$ whereas $\mathrm{KcO}$, also measured in nine patients, was 0 reduced only in the two patients with emphysema (Nos음 1 and 3).

Mean Pemax was $112 \mathrm{~cm} \mathrm{H}_{2} \mathrm{O}$ (95\% pred), indicating normal expiratory muscle strength (table 3$)$. Only one patient, who had had a thoracotomy (No 4), had a

Table 2 Lung function in the 11 patients

\begin{tabular}{|c|c|c|c|c|c|c|}
\hline $\begin{array}{l}\text { Patient } \\
\text { No }\end{array}$ & $\begin{array}{l}\text { Vital capacity } \\
\text { (\% pred) }\end{array}$ & $\begin{array}{l}\text { Supine fall } \\
\text { in } V C(\%)\end{array}$ & $\begin{array}{l}T L C \\
\text { (\% pred) }\end{array}$ & $\begin{array}{l}R V \\
\text { (\% pred) }\end{array}$ & $\begin{array}{l}\text { TLco } \\
\text { (\% pred) }\end{array}$ & $\begin{array}{l}\text { Kco } \\
\text { (\% pred) }\end{array}$ \\
\hline $\begin{array}{r}1 \\
2 \\
3 \\
4 \\
5 \\
6 \\
7 \\
8 \\
9 \\
10 \\
11\end{array}$ & $\begin{array}{l}2.9(91) \\
2.6(68) \\
2 \cdot 5(72) \\
1.7(36) \\
2.5(88) \\
4.2(69) \\
4.6(135) \\
2.6(68) \\
1.9(61) \\
3.7(73) \\
2.9(75)\end{array}$ & $\begin{array}{r}10 \\
0 \\
22 \\
* \\
10 \\
22 \\
17 \\
19 \\
0 \\
8 \\
10\end{array}$ & $\begin{array}{r}94 \\
* \\
87 \\
56 \\
114 \\
74 \\
* \quad \\
93 \\
85 \\
104 \\
82\end{array}$ & $\begin{array}{l}117 \\
* \\
126 \\
90 \\
145 \\
78 \\
* \\
121 \\
107 \\
101 \\
78\end{array}$ & $\begin{array}{r}39 \\
88 \\
51 \\
53 \\
108 \\
70 \\
* \quad \\
82 \\
71 \\
113 \\
56\end{array}$ & $\begin{array}{r}59 \\
* \\
59 \\
132 \\
103 \\
108 \\
* \\
119 \\
91 \\
133 \\
88\end{array}$ \\
\hline $\begin{array}{l}\text { Mean } \\
\text { SD }\end{array}$ & $\begin{array}{l}2.9(76) \\
0.9(24)\end{array}$ & $\begin{array}{r}11 \cdot 8 \\
8 \cdot 1\end{array}$ & $\begin{array}{l}87 \cdot 7 \\
16 \cdot 8\end{array}$ & $\begin{array}{r}107 \cdot 0 \\
22 \cdot 7\end{array}$ & $\begin{array}{l}73 \cdot 1 \\
24 \cdot 7\end{array}$ & $\begin{array}{l}99 \cdot 1 \\
27 \cdot 7\end{array}$ \\
\hline
\end{tabular}

Table 3 Respiratory muscle strength: results of voluntary manoeuvres in the 11 patients

\begin{tabular}{|c|c|c|c|c|c|c|c|c|c|}
\hline \multirow[b]{2}{*}{ Patient No } & \multirow[b]{2}{*}{ Sex } & \multicolumn{2}{|l|}{ PEmax } & \multicolumn{2}{|l|}{ PImax } & \multicolumn{2}{|l|}{ Sniff Pdi } & \multicolumn{2}{|c|}{ PdiPımax } \\
\hline & & $\mathrm{cm} \mathrm{H}_{2} \mathrm{O}$ & $\%$ pred & $\mathrm{cm} \mathrm{H}_{2} \mathrm{O}$ & $\%$ pred & $\mathrm{cm} \mathrm{H}_{2} \mathrm{O}$ & $\%$ pred & $\mathrm{cm} \mathrm{H}_{2} \mathrm{O}$ & $\%$ pred \\
\hline $\begin{array}{r}1 \\
2 \\
3 \\
4 \\
5 \\
6 \\
7 \\
8 \\
9 \\
10 \\
11\end{array}$ & $\begin{array}{l}\mathbf{M} \\
\mathbf{M} \\
\mathbf{F} \\
\mathbf{M} \\
\mathbf{F} \\
\mathbf{M} \\
\mathbf{M} \\
\mathbf{M} \\
\mathbf{F} \\
\mathbf{M} \\
\mathbf{M}\end{array}$ & $\begin{array}{r}84 \\
88 \\
92 \\
77 \\
64 \\
104 \\
188 \\
236 \\
80 \\
124 \\
95\end{array}$ & $\begin{array}{r}70 \\
70 \\
96 \\
57 \\
71 \\
112 \\
147 \\
182 \\
83 \\
85 \\
69\end{array}$ & $\begin{array}{l}52 \\
56 \\
45 \\
27 \\
52 \\
52 \\
64 \\
48 \\
42 \\
52 \\
45\end{array}$ & $\begin{array}{l}60 \\
65 \\
66 \\
31 \\
75 \\
72 \\
77 \\
57 \\
63 \\
61 \\
52\end{array}$ & $\begin{array}{l}67 \\
65 \\
50 \\
35 \\
57 \\
85 \\
50 \\
82 \\
50 \\
87 \\
58\end{array}$ & $\begin{array}{l}45 \\
44 \\
41 \\
24 \\
47 \\
57 \\
34 \\
55 \\
41 \\
59 \\
39\end{array}$ & $\begin{array}{r}35 \\
22 \\
40 \\
5 \\
22 \\
7 \\
40 \\
50 \\
22 \\
22 \\
40\end{array}$ & $\begin{array}{r}32 \\
20 \\
62 \\
5 \\
34 \\
6 \\
37 \\
46 \\
34 \\
20 \\
37\end{array}$ \\
\hline $\begin{array}{l}\text { Mean } \\
\text { SD }\end{array}$ & & $\begin{array}{r}112.0 \\
52.9\end{array}$ & $\begin{array}{l}94 \cdot 7 \\
38 \cdot 4\end{array}$ & $\begin{array}{r}48 \cdot 7 \\
9 \cdot 4\end{array}$ & $\begin{array}{l}61 \cdot 7 \\
12 \cdot 7\end{array}$ & $\begin{array}{l}62 \cdot 3 \\
16 \cdot 7\end{array}$ & $\begin{array}{r}44.6 \\
9.4\end{array}$ & $\begin{array}{l}27 \cdot 7 \\
14 \cdot 4\end{array}$ & $\begin{array}{l}30 \cdot 3 \\
16 \cdot 8\end{array}$ \\
\hline Normal val & $\begin{array}{l}\text { : mea } \\
\text { M } \\
\text { F }\end{array}$ & $\begin{array}{r}154 \\
94\end{array}$ & $\begin{array}{l}(82) \\
(33)\end{array}$ & $\begin{array}{r}114 \\
71\end{array}$ & $\begin{array}{l}(36) \\
(27)\end{array}$ & $\begin{array}{l}148 \\
121\end{array}$ & $\begin{array}{l}(24) \\
(25)\end{array}$ & $\begin{array}{l}108 \\
65\end{array}$ & $\begin{array}{l}(30) \\
(31)\end{array}$ \\
\hline
\end{tabular}

Pemax, Pimax - static maximum expiratory and inspiratory pressure measured at the mouth; sniff Pdi-transdiaphragmatic pressure $\sigma$ measured during a short, sharp maximal sniff; PdiPimax-transdiaphragmatic pressure measured during a maximal static inspiratory effort at residual volume against a closed valve.

${ }^{*}$ From Leech et $a l^{13}$ and Miller et al. ${ }^{6}$ 
Table 4 Phrenic nerve stimulation: results in the 11 patients

\begin{tabular}{|c|c|c|c|c|c|c|}
\hline \multirow[b]{2}{*}{ Patient no } & \multirow[b]{2}{*}{ Affected side } & \multicolumn{2}{|c|}{ Unilateral diaphragm pressure $\left(\mathrm{cm}_{2} \mathrm{O}\right)$} & \multirow{2}{*}{$\begin{array}{l}\text { Bilateral } \\
\text { diaphragm } \\
\left(\mathrm{cm} \mathrm{H}_{2} \mathrm{O}\right)\end{array}$} & \multicolumn{2}{|c|}{ Conduction time (ms) } \\
\hline & & Affected side & Normal side & & Affected side & Normal side \\
\hline $\begin{array}{r}1 \\
2 \\
3 \\
4 \\
5 \\
6 \\
7 \\
8 \\
9 \\
10 \\
11\end{array}$ & $\begin{array}{l}\mathbf{L} \\
\mathbf{L} \\
\mathbf{L} \\
\mathbf{R} \\
\mathbf{L} \\
\mathbf{L} \\
\mathbf{R} \\
\mathbf{L} \\
\mathbf{L} \\
\mathbf{L} \\
\mathbf{R}\end{array}$ & $\begin{array}{l}0 \\
3 \\
2 \\
0 \\
5 \\
2 \\
0 \\
2 \\
0 \\
0 \\
0\end{array}$ & $\begin{array}{r}6 \\
9 \\
6 \\
8 \\
7 \\
17 \\
15 \\
8 \\
12 \\
6 \\
7\end{array}$ & $\begin{array}{r}6 \\
10 \\
6 \\
9 \\
13 \\
17 \\
17 \\
11 \\
12 \\
6 \\
9\end{array}$ & $\begin{array}{r}12 \\
7 \\
16 \\
\dagger \\
18 \\
17 \\
15 \\
8 \\
12 \\
35 \\
11\end{array}$ & $\begin{array}{r}8 \\
7 \\
7 \\
8 \\
7 \\
9 \\
6 \\
7 \\
8 \\
10 \\
8\end{array}$ \\
\hline $\begin{array}{l}\text { Mean } \\
\text { SD }\end{array}$ & $\begin{array}{l}1.3 \\
1.7\end{array}$ & $\begin{array}{l}9 \cdot 3 \\
4 \cdot 0\end{array}$ & $\begin{array}{r}11 \cdot 1 \\
3 \cdot 5\end{array}$ & & & \\
\hline \multicolumn{2}{|c|}{ Normal values (range)* } & \multicolumn{2}{|c|}{$\begin{array}{l}\text { Diaphragm pressure } \\
\text { R5.4-12.4 } \\
\text { L7.8-15.3 } \\
\text { Bilateral } 14 \cdot 6-33 \cdot 4\end{array}$} & $\begin{array}{l}\text { Conduction } \\
6 \cdot 0-9 \cdot 5 \\
5 \cdot 5-9 \cdot 5\end{array}$ & & \\
\hline
\end{tabular}

*From Mier et al. ${ }^{910}$

†M wave too small for determination of conduction time.

Pemax value significantly less than predicted. Mean maximum inspiratory muscle strength (PImax), however, was only $49 \mathrm{~cm} \mathrm{H}_{2} \mathrm{O}$ (62\% pred), consistent with inspiratory muscle weakness. Diaphragm strength, as measured by sniff Pdi (mean $62 \mathrm{~cm} \mathrm{H} \mathrm{H}_{2} \mathrm{O}$, $45 \%$ pred) and PdiPimax (mean $28 \mathrm{~cm} \mathrm{H}_{2} \mathrm{O}, 45 \%$ pred) and PdiPimax (mean $28 \mathrm{~cm} \mathrm{H}_{2} \mathrm{O}, 30 \%$ pred), was also reduced in all 11 patients.

Unilateral twitch Pdi was reduced or undetectable on the affected side, confirming hemidiaphragm dysfunction in all 11 patients (table 4), whereas on the unaffected side it was normal. Mean bilateral twitch Pdi was also reduced, confirming that overall diaphragm function was impaired. Phrenic nerve conduction time was prolonged on the affected side in nine out of 11 patients (table 4), consistent with phrenic nerve dysfunction. It was normal in two: patient 2 , studied one year after aortic valve replacement, and patient 8 , who had had a chest infection. It was normal on the unaffected side in all 11 patients.

\section{Discussion}

This study confirmed the presence of appreciable inspiratory muscle weakness due to diaphragm dysfunction in 11 patients with a raised hemidiaphragm of recent onset. Unilateral hemidiaphragm dysfunction was confirmed by the greatly reduced twitch pressure in response to phrenic nerve stimulation on the affected side. This appears to be a useful test with which to confirm and quantify hemidiaphragm dysfunction or paralysis and is more discriminating than fluoroscopy, which cannot quantify the degree of weakness and has a false positive rate of $6 \%$ in normal subjects. ${ }^{3}$ We were unable to locate the phrenic nerves in a twelfth patient, a woman with considerable obesity, who was therefore excluded from the analysis. This was not regarded as a false negative result since it was clear from our inability to obtain a diaphragmatic electromyogram on either side that the phrenic nerves had not been located.

Our study showed inspiratory and diaphragmatic weakness in all patients confirmed to have hemidiaphragm paralysis or dysfunction of recent onset. Impaired muscle function was more consistently present than in the recent study by Lisboa et al of patients with longstanding hemidiaphragm elevation. ${ }^{2}$ This discrepancy is, however, compatible with their suggestion that the apparently normal inspiratory function found in some patients with longstanding paralysis may be due to hypertrophy of the contralateral hemidiaphragm as this would not have had time to occur in our patients.

It is sometimes thought that unilateral hemidiaphragm paralysis does not give rise to functional abnormality or symptoms. Breathlessness has, however, been reported in $10-24 \%$ of such patients. ${ }^{11}$ In the study of Lisboa $e t$ al all five patients with diaphragm weakness due to longstanding hemidiaphragm paralysis resulting from phrenic nerve crush complained of dyspnoea, although extensive tuberculous sequelae may also have contributed. Of their 10 patients in whom the cause of the longstanding hemidiaphragm elevation was unknown, both the patients with associated cardiopulmonary disease and three of the eight patients with no associated path- 
ological condition were breathless.

In some of our 11 patients breathlessness may have been the result of inspiratory muscle dysfunction superimposed on another pathological condition, such as airways obstruction, which increases the demands of the respiratory muscles. All patients had, however, noticed a change in breathlessness after the onset of the unilateral diaphragm paralysis that was not related to a deterioration in the lung disease.

Patients may be more aware of breathlessness at the time of onset of unilateral diaphragm paralysis; for instance, patient 7 was initially breathless but had improved by the time of study three months later, even though he still had residual inspiratory muscle weakness.

PImax may already be reduced in patients with severe chronic airways obstruction ${ }^{12}$ owing to the mechanical disadvantage of increased lung volume. This was unlikely, however, to be contributing significantly to inspiratory muscle weakness in our patients since total lung capacity was not increased by more than $14 \%$ of the predicted value. ${ }^{12}$

In conclusion, measurement of unilateral twitch Pdi during phrenic nerve stimulation is a useful test with which to confirm and quantify unilateral hemidiaphragm dysfunction. Recent onset of hemidiaphragm paralysis or dysfunction is associated with a reduction in maximal transdiaphragmatic pressure, leading to reduced inspiratory capacity. This may explain the increase in breathlessness and decrease in exercise tolerance associated with the condition, which are exacerbated by any additional pathological condition, thus increasing the demands of the respiratory muscles. Prolongation of phrenic nerve conduction time confirms a neuropathic cause.

\section{References}

1 Arborelius M, Lilja B, Senyk J. Regional and Total Lung Function in Patients with Hemidiaphragmatic Paralysis. Respiration 1975;32:253-64.

2 Lisboa C, Paré PD, Pertuze J, et al. Inspiratory Muscle Function in Unilateral Diaphragmatic Paralysis. $\mathrm{Am}$ के Rev Respir Dis 1986;134:488-92.

3 Alexander C. Diaphragm movements and the diagnosis of diaphragmatic paralysis. Clin Radiol 1966;17:79-83. $\vec{\omega}$

4 Black LE, Hyatt RE. Maximal respiratory pressures: normal values and relationship to age and sex. Am Rev Respir Dis 1969;99:696-702.

5 Agostoni E, Rahn H. Abdominal and thoracic pressures at different lung volumes. J Appl Physiol 1960; 15: 1087-92.

6 Miller JM, Moxham J, Green M. The maximal sniff in the assessment of diaphragm function in man. Clin $\mathrm{Sci}$ 1985;69:91-6.

7 Cotes JE. Lung function: assessment and application in medicine. 4th ed. Oxford: Blackwell Scientific Publications, 1978

8 Allen SM, Hunt B, Green M. Fall in vital capacity with posture. Br J Dis Chest 1985;79:267-71.

9 Mier A, Brophy C, Moxham J, Green M. Phrenic nerve stimulation-normal values for twitch Pdi [abstract]. Clin Sci 1986;70:194P.

10 Mier A, Brophy C, Moxham J, Green M. Phrenic nerve o conduction time in normals [abstract]. Clin Sci 1986;70:193P.

11 Douglass BE, Clagett OT. The prognosis in idiopathic diaphragmatic paralysis. Chest 1960;37:294-7.

12 Rochester DF, Braun NMT. Determinants of maximal inspiratory pressure in chronic obstructive pulmonary disease. Am Rev Respir Dis 1985;132:42-7.

13 Leech JA, Ghezzo H, Stevens D, Becklake MR. Respiratory pressures and function in young adults. $\mathrm{Am}$ Rev Respir Dis 1983;128:17-23. 